\title{
74. Writing to an Indexed Sequential File
}

\section{Example}

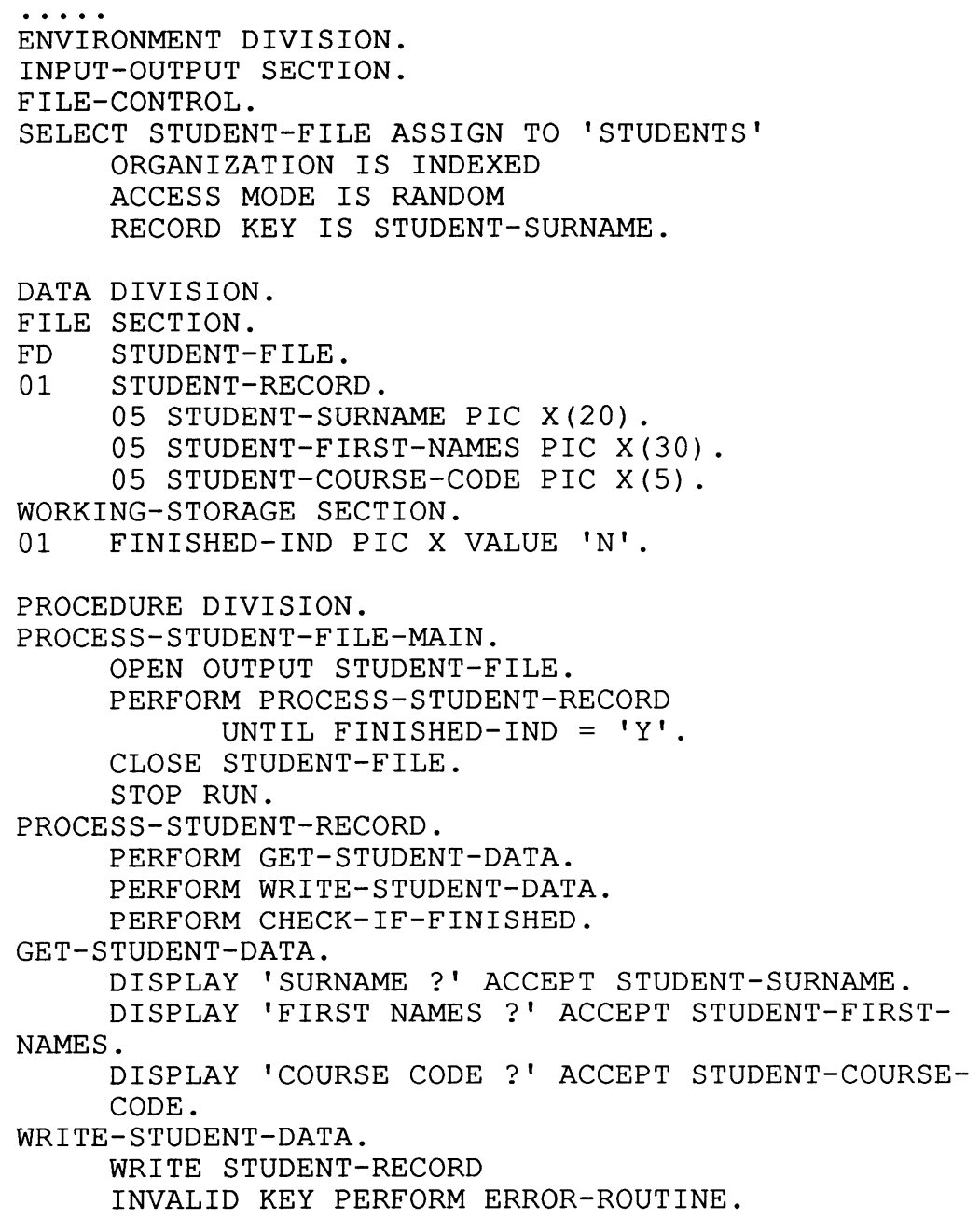

Write and Read statements must contain a command saying what the computer should do if the key given is invalid (e.g. if two records have the same key).

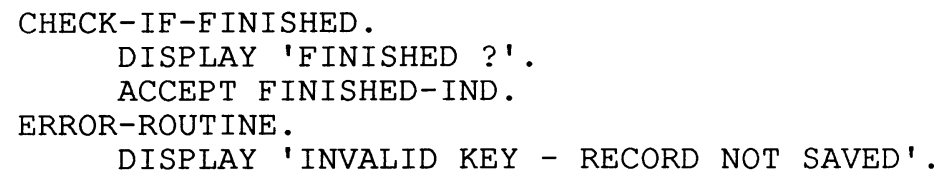

Exercise

Write a program which allows a staff-file to be built up containing each employee's surname, first names, address, job title, department, salary. 